www.nature.com/clinicalpractice/uro

\title{
Technology Insight: radioguided sentinel lymph node dissection in the staging of prostate cancer
}

Avi Beri and Günter Janetschek

Nature Clinical Practice Urology (2006) 3: 602-610 [doi:10.1038/ncpuro0625]

doi:10.1038/ncpuro0658

\section{ERRATUM}

In the November 2006 issue, in the Technology Insight Review by Beri and Janetschek, the third label on the $x$ axis of Figure 4 describing the anatomic location of sentinel lymph nodes was published incorrectly as "Common iliac". This should have appeared as "External iliac". The correct figure is reproduced below with the original published legend.

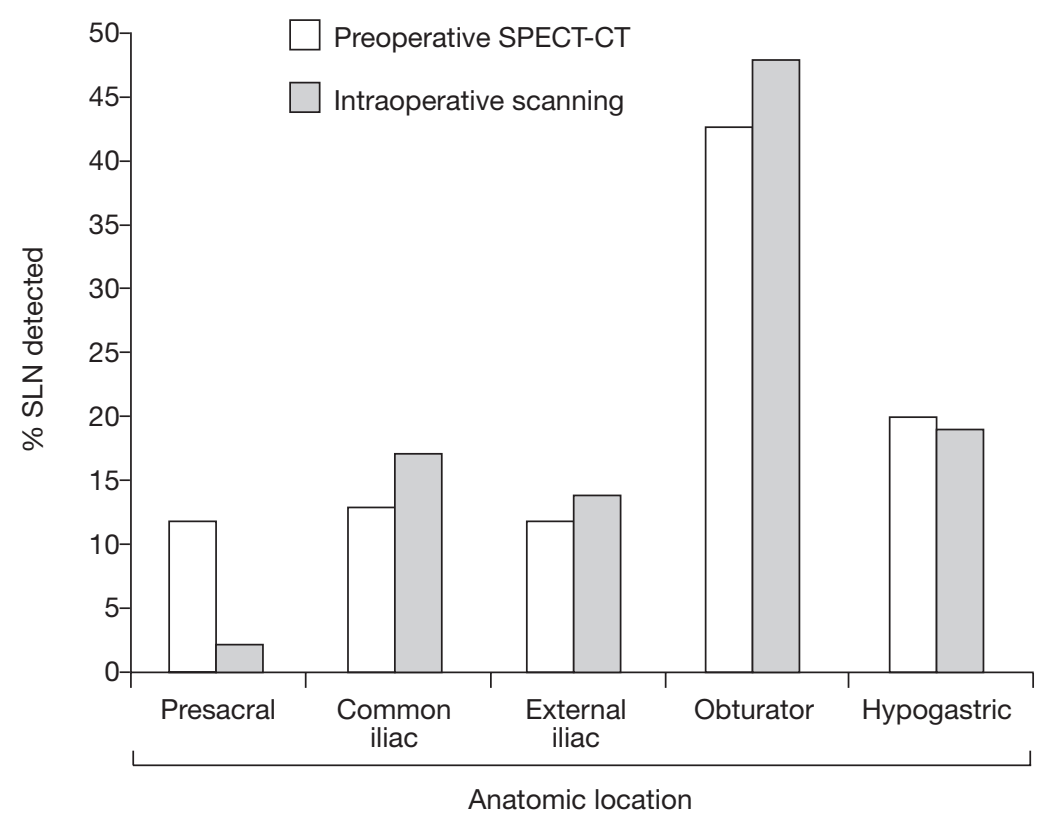

Figure 4 Regional distribution of sentinel lymph nodes detected on preoperative SPECT-CT and intraoperatively. ${ }^{25}$ Multidetector cameras, in combination with cross-sectional imaging, can be used to obtain precise anatomic localization of the lymph nodes. SPECT-CT is an imaging technique in which images obtained by SPECT (which can take up to $20 \mathrm{~min}$ and are, therefore, subject to movement-induced blurring) and conventional (instantaneous) CT are combined, to improve image quality and resolution. Abbreviation: SPECT, single-photon-emission computed tomography. 